\title{
Head and neck irradiation modulates pharmacokinetics of 5 -fluorouracil and cisplatin
}

\author{
Chen-Hsi Hsieh ${ }^{1,2,3}$, Mei-Ling Hou ${ }^{2}$, Meng-Hsuan Chiang ${ }^{2}$, Hung-Chi Tai ${ }^{4}$, Hui-Ju Tien', Li-Ying Wang ${ }^{7}$, \\ Tung-Hu Tsai ${ }^{2,6^{*}}$ and Yu-Jen Chen ${ }^{2,4,5^{*}}$
}

\begin{abstract}
Background: 5-fluorouracil (5-FU) and cisplatin (CDDP) are used to enhance radiotherapy (RT) effect for head and neck (HN) cancers. However, the effect of local RT on systemic chemotherapeutics remains unclear. Here, we evaluated the influence of HN irradiation on the pharmacokinetics (PK) of 5-FU and CDDP in rats as experimental model.
\end{abstract}

Methods: The radiation dose distributions of HN cancer patients were determined for the low dose areas, which are generously deposited around the target volume. Two Gy and 0.5 Gy RT were selected. Single-fraction radiation was delivered to the $\mathrm{HN}$ of Sprague-Dawley rats. $5-\mathrm{FU}$ at $100 \mathrm{mg} / \mathrm{kg}$ or CDDP at $5 \mathrm{mg} / \mathrm{kg}$ was intravenously infused 24 hours after radiation.

Results: Radiation at 2 Gy reduced the area under the plasma concentration vs. time curve (AUC) of 5-FU and CDDP by $16 \%$ and $29 \%$ compared to non-irradiated controls, respectively. This was accompanied by incremental total plasma clearance values. Intriguingly, low dose radiation at 0.5 Gy resulted in a similar pharmacokinetic profile, with a $17 \%$ and $33 \%$ reduction in the AUC of 5-FU and CDDP, respectively. The changes in AUC of bile, which increases with RT, were opposite to AUC of plasma for both drugs.

Conclusions: The local HN RT could modulate systemic PK of 5-FU and CDDP in rats. This unexpected RT-PK phenomena may provide a reference for adjustment of drug administration and is worthy of further investigation.

Trial registration: ClinicalTrials.gov ID NCT01755585 and NCT01609114

Keywords: 5-Fluorouracil (5-FU), Cisplatin (CDDP), Concurrent chemoradiation therapy (CCRT), Head and neck, Pharmacokinetics, Radiotherapy

\section{Background}

The concurrent use of chemotherapy during radiation therapy (CCRT) is now the important treatment stratagem as definitive treatment [1] or adjuvant setting for locally advanced head and neck cancer [2,3]. For these cases, 5-Fluorouracil (5-FU) and cisplatin (CDDP) are the most commonly used agents in CCRT to improve the treatment outcome [4-6]. As radiation techniques improving, that three-dimensional conformal radiotherapy (3DCRT), intensity-modulated radiotherapy (IMRT), and image-guided arc therapy such as helical tomotherapy

\footnotetext{
* Correspondence: thtsai@ym.edu.tw; chenmdphd@gmail.com

${ }^{2}$ Institute of Traditional Medicine, School of Medicine, National Yang-Ming University, 155, Li-Nong Street Section 2, Taipei 112, Taiwan

${ }^{4}$ Department of Radiation Oncology, Mackay Memorial Hospital, 92, Chung-Shan North Road, Taipei, Taiwan

Full list of author information is available at the end of the article
}

(HT) are applied for cancer treatment worldwide. These are supposed to produce greater target dose conformity and better critical organ sparing effects with lower toxicity to normal tissues [7-11]. However, these dosepainting techniques usually produce a generous lowdose distribution to the torso which biological effect remains unclear $[12,13]$.

Radiation therapy (RT) is classically considered as a local treatment. However, irradiation not only can cause direct DNA damage effects but also can send signals to neighboring cells named as the bystander effects $[14,15]$ or caused longer-range effects called abscopal effects [16]. Recently, we report that abdominal irradiation no matter 0.5 Gy considering as off-target area in clinical practice or $2 \mathrm{~Gy}$, the daily treatment dose, could significantly modulate the systemic pharmacokinetics (PK) of 
5-FU in an experimental rat model [17]. Furthermore, our next study confirm that local pelvic irradiation with the liver and kidneys excluded also modulated the systemic PK of 5-FU through stimulating the release of matrix metalloproteinase-8 (MMP-8) [18]. The field of RT in the study is excluded the live and the kidneys [18]. However, there are still a few parts of intestines being involved in the whole pelvic field. Leukocyte infiltration of rat small intestine could be induced by 5-FU [19] and the passive transport and carrier-mediated transport in intestinal also influences uptake of 5-FU [20]. Given that head and neck cancers are common in cancer population and CCRT is widely used in clinical practice, whether the RT-PK phenomena we observed in abdomen and pelvis RT with 5-FU exists in head and neck region is an important issue to be addressed.

CDDP (cis-diammine-dichloro-platinum) is an inorganic molecule, with a central platinum atom surrounded by two chlorine atoms and two ammonia molecules [21]. It is often used as an attractive chemotherapy drug and broadly used for the treatment of various forms of malignant tumors. There are five major characteristics that are considered to be responsible for the cytotoxic effects of cisplatin. As a radiosensitizer, its affinity with the thermalized electron created by radiation induced ionization within the DNA molecule and may lead to irreparable damage to the DNA [22]. Moreover, the inhibition of sublethal damage repair (SLDR) by cisplatin is demonstrated by experiments on oxic mammalian cells [23]. Cisplatin also has the ability to arrest cells in the G2 phase of the cell cycle and, possibly, to induce their death [24-26]. Research showed that a cell's relative radiosensitivity is determined by the cell cycle phase. Cells are most radiosensitive in the G2/M phase, less sensitive in the $\mathrm{G} 1$ phase and least sensitive during the latter part of the $S$ phase [27]. In addition, the suppression of tumour neovascularization by cisplatin has been identified recently and is under further investigation [28].

In the present study, we investigated the effect of head and neck RT, including therapeutic fraction size and offtarget dose, on pharmacokinetics of 5-FU and CDDP in rats. The issues of advance in dose-painting techniques and adoption of CCRT did not exist in the past era of conventional 2DRT. Therefore, the conceptual correlation to clinical practice in humans is drawn from point of view of the radiation oncologist in this translational research.

\section{Methods}

\section{Subjects}

Prior to pharmacokinetic analysis in rats, we demonstrated the radiation dose distributions in a head and neck cancer patient to show the dose-painting concept that low dose area generously deposited around highdose target volume.

\section{Targeting and treatment planning}

Although only treated by one mode of RT, four sets of radiation planning were performed for each patient including that for conventional radiotherapy (2DRT), 3DCRT, IMRT, and HT. The PINNACLE ${ }^{3}$ version $7.6 \mathrm{c}$ planning system for the former three modes and the $\mathrm{Hi}$ Art Planning system for tomotherapy (Tomotherapy, Inc., Madison, Wisconsin, USA) were used. The treatment fields for 2DRT, 3DCRT, and IMRT were 2, 5, and 7, respectively. The field width, pitch, and modulation factor (MF) used in tomotherapy were $2.5 \mathrm{~cm}, 0.32$, and 3.5 , respectively. A fraction size of 2 Gy was chosen as daily dose. For the radiation dose to the normal tissues, an isodose line of 0.5 Gy was designed to represent the off-target, general low-dose area during daily treatment. Notably, there is no dose-painting result in 2DRT planning, the technique in the past era. Patient data are collected with the approval of the Institutional Review Board of Far Eastern Memorial Hospital (FEMH-IRB-100163-F).

\section{Materials and reagents}

The 5-FU/CDDP and high-performance liquid chromatography (HPLC)-grade methanol were purchased from Sigma Chemicals (St. Louis, MO, USA) and Tedia Company, Inc. (Fairfield, OH, USA), respectively. Milli-Q grade (Millipore, Bedford, MA, USA) water was used for the preparation of solutions and mobile phases.

\section{Animals and sample preparation}

Adult, male Sprague-Dawley rats (300 \pm 20 g body weight) were provided by the Laboratory Animal Center at National Yang-Ming University (Taipei, Taiwan). The rats were anesthetized with urethane $1 \mathrm{~g} / \mathrm{ml}$ and $\alpha$-chloralose $0.1 \mathrm{~g} / \mathrm{ml}$ ( $1 \mathrm{ml} / \mathrm{kg}$, i.p.), and were immobilized on a board to undergo computed tomography for simulation of the one phase of head and neck RT field. The cranial margin was set at $5 \mathrm{~mm}$ above the head and the caudal margin was set above the head of humerus. (Figure 1) The conventional technique with anterior-posterior (AP) and PA portal by 6-MV X-ray was delivered by an linear accelerator (Varian Medical Systems, Palo Alto, CA). The experimental animals were randomized to three separate experiments for no drug, CDDP and 5-FU administration and each experiment included at least 6 rats for each with control (0 Gy), 0.5, and 2 Gy group. All experimental animal surgery procedures were reviewed and approved by the animal ethics committee of Far Eastern Memorial Hospital, Taiwan (FEMH- 100-1-18-A).

Jarugula et al. [29] proved that the dose-normalized area under the curve (AUC) is significantly higher after administration of $100 \mathrm{mg} / \mathrm{kg}$ than after $50 \mathrm{mg} / \mathrm{kg}$ or $10 \mathrm{mg} / \mathrm{kg}$. Thus, we chose $100 \mathrm{mg} / \mathrm{kg}$ as a feasible $5-\mathrm{FU}$ dose in rats for examination of 5-FU pharmacokinetic parameters, based on previous reports [17,29]. 


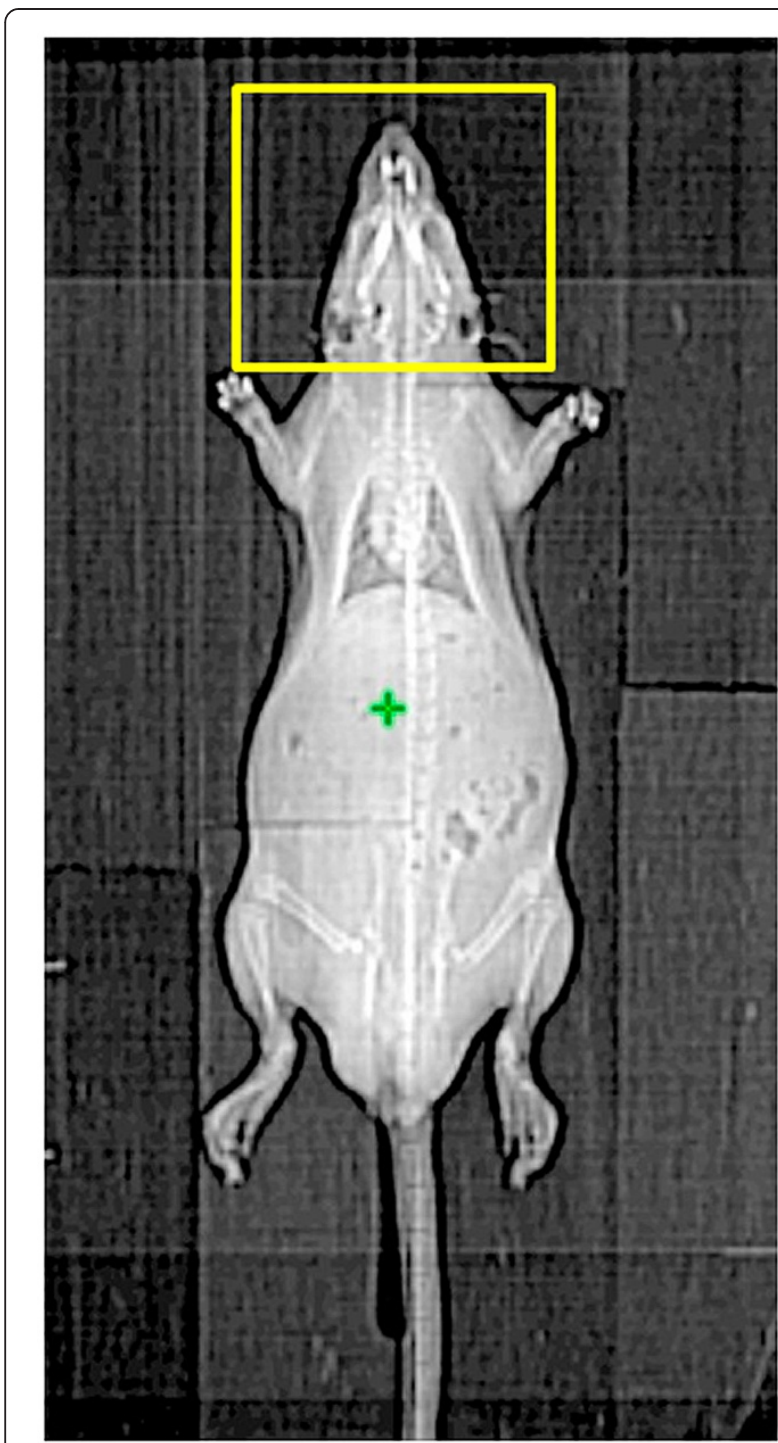

Figure 1 Computed tomography was used for simulation of the head and neck field. The cranial margin was set at $5 \mathrm{~mm}$ above the head and the caudal margin was set above the head of humerus. Conventional radiotherapy was used to deliver the radiation dose via the anterior-posterior (AP) and PA portals.

The LD50 of CDDP for rat with oral, intraperitoneal, subcutaneous, intravenous is $25,7,8$ and $11 \mathrm{mg} / \mathrm{kg}$, respectively [30]. Therefore, we chose $50 \%$ of LD50 of intravenous CDDP, $5 \mathrm{mg} / \mathrm{kg}$, as a feasible dose in rats for examination of CDDP pharmacokinetic parameters.

Twenty hours after RT, the rats were administered 5-FU at $100 \mathrm{mg} / \mathrm{kg}$ or $5 \mathrm{mg} / \mathrm{kg}$ CDDP in $2 \mathrm{~mL}$ of normal saline by intravenous infusion into the femoral vein over a 2-min period. A $150-\mu \mathrm{L}$ blood sample was withdrawn from the jugular vein with a fraction collector according to a programmed schedule at 5, 15, 30, 45, $60 \mathrm{~min}, 1.5,2,2.5$, and $3 \mathrm{~h}$ following drug administration. After centrifugation and vortexing, the upper organic layer was transferred to a new tube and evaporated to dryness under flowing nitrogen. The dried residue was reconstituted with $50 \mu \mathrm{l}$ of Milli-Q water (Millipore). A $20-\mu \mathrm{L}$ aliquot of the solution was injected to the HPLC-UV system.

\section{Liquid chromatography \\ 5-FU}

Chromatographic analysis is performed on a Model LC20AT HPLC system (Shimadzu, Tokyo, Japan) equipped with a Model SPD-20A wavelength UV detector, SIL-20 AC autosampler, and an LC Solution data processing system. A LiChroCART RP-18e column (Purospher, $250 \mathrm{~mm}, 5 \mu \mathrm{m}$, Merck, Darmstadt, Germany) with a LiChroCART 4-4 guard column is used for separation. The mobile phase comprised $10 \mu \mathrm{M}$ potassium phosphate-methanol (99: 1, v/v, pH 4.5 adjusted by $85 \%$ phosphoric acid), and the flow rate of the mobile phase is $1 \mathrm{ml} / \mathrm{min}$. The detection wavelength is set at $266 \mathrm{~nm}$. Under these conditions, the retention time of 5 -FU is $5.4 \mathrm{~min}$. The linearity of calibration curves is demonstrated by the good determination coefficients (r2) obtained for the regression line. Good linearity is achieved over the range of $0.01-5 \mu \mathrm{g} / \mathrm{ml}$, with all coefficients of correlation greater than 0.998. All samples are freshly prepared, including the standard solutions, from the same stock solution $(5 \mathrm{mg} / \mathrm{mL})$. The $0.01-\mu \mathrm{g} / \mathrm{mL}$ limit of quantification is defined the lowest concentration on the calibration curve that could be measured routinely with acceptable bias and relative SD. The overall mean precision, defined by the relative $\mathrm{SD}$, ranged from $0.2 \%$ to $11.0 \%$. Analytical accuracy is expressed as the percentage difference of the mean observed values compared to known concentrations varying from $-10.0 \%$ to $14.0 \%$. The recovery results for concentrations of $0.1-10 \mu \mathrm{g} / \mathrm{mL}$ are $92.0 \%-94.0 \%$.

\section{CDDP}

The HPLC system consist of a chromatographic pump (LC-20AT, Shimadzu, Kyoto, Japan), autosampler (SIL20AT, Shimadzu), diode array detector (SPD-M20A, Shimadzu), and degasser (DG-240). A reversed-phase C18 column $(4.6 \times 250 \mathrm{~mm}$, particle size $5 \mu \mathrm{m}$, Eclipse XDB, Agilent, Palo Alto, CA, USA) is used for the HPLC separation. The mobile phase is composed of acetonitrile-10 $\mathrm{mM}$ monosodium phosphate $(\mathrm{pH} 3.0$ adjusted by orthophosphoric acid) (70:30, v/v) at a flow-rate of $1.0 \mathrm{ml} / \mathrm{min}$. The chromatographic run time is $13 \mathrm{~min}$ and the detection wavelength is set at $254 \mathrm{~nm}$. The mobile phase is filtered through a $0.45 \mu \mathrm{m}$ Millipore membrane filter and degassed by sonication 2510R-DTH (Bransonic, CT, USA) before use. The stock solution of CDDP in 50\% acetonitrile $(500 \mu \mathrm{g} / \mathrm{ml})$ is diluted with $50 \%$ acetonitrile to make serial concentrations of the working standard solutions $(1,5,10$, 50 and $100 \mu \mathrm{g} / \mathrm{ml}$ ). Plasma is separated by centrifuging the 
blood sample at $6000 \mathrm{rpm}$ for $10 \mathrm{~min}$ at 4 OC. Calibration standards are prepared by $5 \mu \mathrm{l}$ of the working standard solution spik with $45 \mu \mathrm{l}$ of blank plasma and bile, and then added $10 \mu \mathrm{l}$ of freshly prepared $10 \%$ diethyldithiocarbamate in $0.2 \mathrm{~N}$ sodium hydroxide into each sample. These samples are put into the water bath at $45^{\circ} \mathrm{C}$ for $30 \mathrm{~min}$ to form the derivatization of CDDP. The $100 \mu \mathrm{l}$ of internal standard solution (containing $10 \mu \mathrm{g} / \mathrm{ml}$ of magnolol dissolved in acetonitrile) is added to the derivative samples for protein precipitation. The samples are vortexed and centrifuged at 12,000 rpm for $15 \mathrm{~min}$, after which, $20 \mu \mathrm{l}$ of supernatants are collected and analysed by the HPLC system. The calibration curves are represented by the peak areas ratio of the CDDP to internal standard spiked in blank samples vs. the concentration of CDDP. The limits of detection (LOD) and the limit of quantification (LOQ) are defined as a signal-to-noise ratio of 3 and the lowest concentration of the linear regression, respectively. The $0.01-\mu \mathrm{g} / \mathrm{mL}$ limit of quantification is defined the lowest concentration on the calibration curve that could be measured routinely with acceptable bias and relative $\mathrm{SD}$. The overall mean precision, defined by the relative $\mathrm{SD}$, ranged from $0.6 \%$ to $2.2 \%$. Analytical accuracy is expressed as the percentage difference of the mean observed values compared to known concentrations varying from $-7.4 \%$ to $1.0 \%$. The recovery results for concentrations of $0.1-10 \mu \mathrm{g} / \mathrm{mL}$ are $80.7 \%-82.9 .0 \%$.

\section{Pharmacokinetics and data analysis}

Pharmacokinetic parameters such as the AUC for concentration $v$ s. time, terminal elimination phase half-life $\left(t_{1 / 2}\right)$, maximum observed plasma concentration (Cmax), mean residence time (MRT), total plasma clearance (CL), volume of distribution at steady state (Vss), and the elimination constant (Kel) were calculated by the pharmacokinetics calculation software WinNonlin Standard Edition, Version 1.1 (Scientific Consulting, Apex, NC, USA) using a compartmental method.

\section{Statistical methods}

The results are presented as means \pm standard deviations. Differences in actuarial outcomes between the groups were calculated using one-way analysis of variance (ANOVA), with post hoc multiple comparisons. All analyses were performed using the Statistical Package for the Social Sciences, version 12.0 (SPSS, Chicago, IL, USA).

\section{Results}

\section{Comparison of treatment plans for different radiation} dosing techniques

A representative example of isodose distribution with 2 Gy to the targets using different techniques is illustrated in Figure 2. It suggests that low dose area generously deposited around target volume especially in the era of advanced, conformal radiation techniques.

\section{Plasma and bile pharmacokinetic parameters of 5-FU and CDDP with head and neck irradiation \\ $5-F U$}

To verify that local RT modulated the systemic pharmacokinetics of 5-FU, we established an experimental model using CT-based planning and one phase of head and neck irradiation in rats merged to our pharmacokinetics assay system. (Figure 1) Of special interest, radiation at 2 Gy
(A) 2DRT
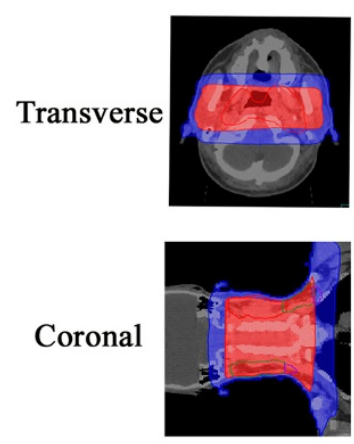

Sagittal

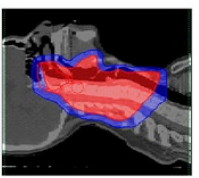

(B) 3DCRT
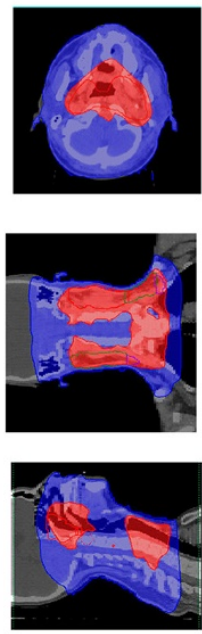

(C) IMRT
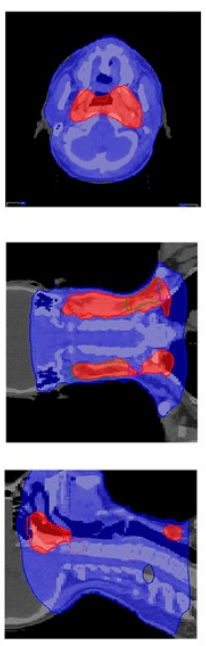

(D) $\mathrm{HT}$
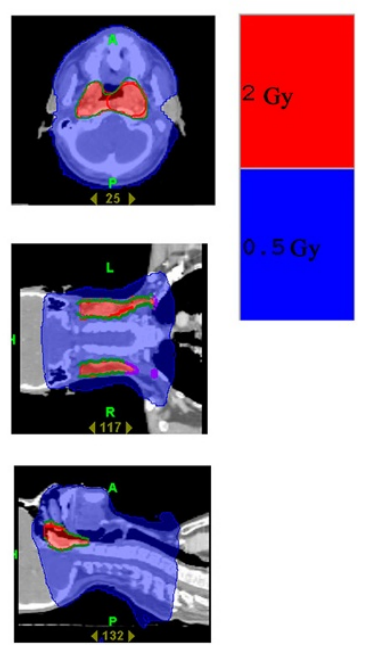

Figure 2 An example of isodose distribution using different irradiation techniques delivering $2 \mathrm{~Gy}$ to the tumor bed for one nasopharyngeal carcinoma patient with transverse, coronal and sagittal view. A) The conventional radiation therapy (2DRT). B) Three-dimensional conformal radiotherapy (3DCRT). C) Intensive modulated radiotherapy (IMRT). D) Helical tomotherapy (HT). 
simulating daily treatment dose to compare with low dose radiation at 0.5 Gy representing a dose deposited in the generous, off-target area in clinical practice. Intriguingly, we found that irradiation markedly reduced the AUC of 5 -FU in rats by $16.9 \%$ at $0.5 \mathrm{~Gy}(p=0.046)$ and $15.9 \%$ at 2 Gy $(p=0.038)$, respectively. (Figure 3A) Irradiation significantly reduced MRT, and by contrast, increased the CL of 5-FU when compared to non-irradiated controls (Table 1). There was no significant difference in the values of Cmax, Vss and $t_{1 / 2}$ within any group.

The AUC of 5-FU in bile of rats after head and neck irradiation markedly increased by $12.2 \%$ at $0.5 \mathrm{~Gy}(p=0.047)$ and $25.0 \%$ at $2 \mathrm{~Gy}(p=0.001)$. (Figure $4 \mathrm{~A})$ Head and neck irradiation significantly decreased Cmax and CL, and in contrast, increased MRT of 5-FU, when compared to nonirradiated controls. Of interest, 2-Gy irradiation decreased Cmax $(P=0.004)$ and CL $(P=0.001)$, and in contrast, increased MRT $(P<0.001)$ of 5 -FU to an extent greater than that of the 0.5 -Gy group. There was no statistically significant difference between the 0.5-Gy and control groups for $\mathrm{T}_{1 / 2}$, clearance value, MRT and Vss. (Table 2).

\section{CDDP}

Head and neck irradiation also modulated the AUC of CDDP in rats by decreasing $33 \%$ at 0.5 Gy $(p=0.021)$ and $29 \%$ at 2 Gy $(p=0.028)$, respectively. (Figure $3 \mathrm{~B}) \mathrm{By}$

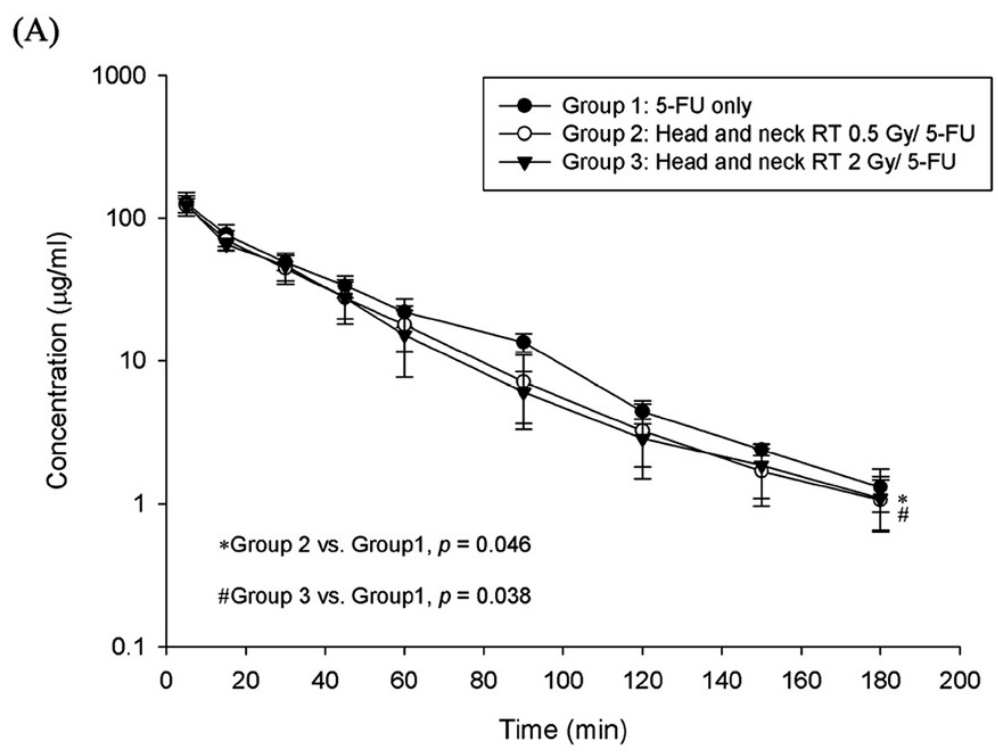

(B)

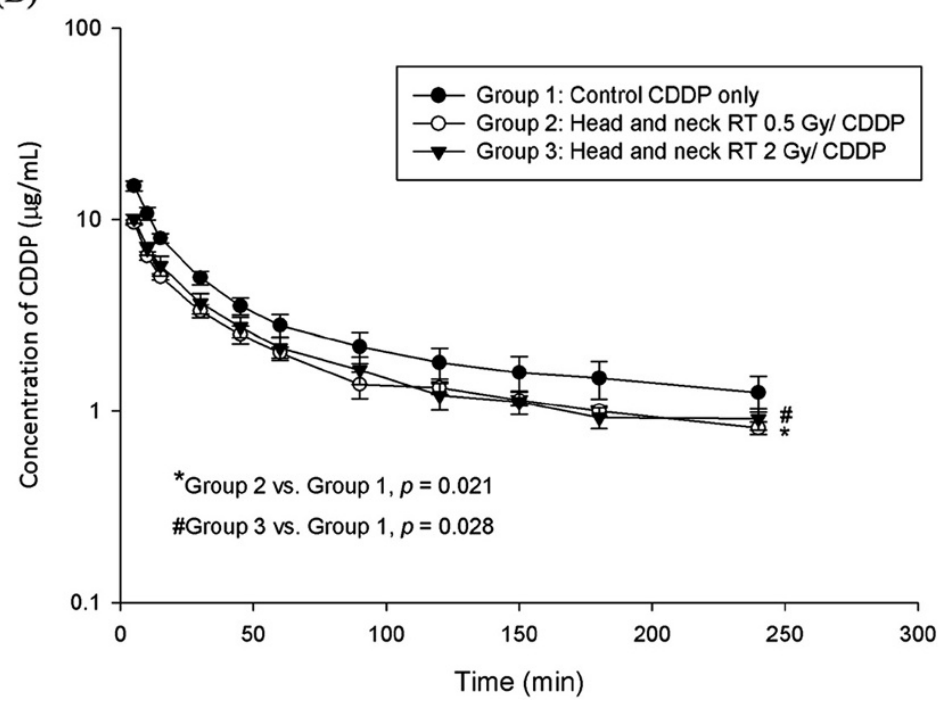

Figure 3 The area under the plasma concentration vs. time curve (AUC) of (A) $5-\mathrm{FU} 100 \mathrm{mg} / \mathrm{kg}$ (B) Cisplatin $5 \mathrm{mg} / \mathrm{kg}$ to rats in the control, 0.5 and 2 Gy groups with head and neck irradiation. 
Table 1 Pharmacokinetic parameters of 5-Fluorouracil (100 $\mathrm{mg} / \mathrm{kg}, \mathrm{i} . \mathrm{v}$.$) in rats plasma after head and neck$ irradiation with and without 0.5 and 2 Gy

\begin{tabular}{lccc}
\hline Parameters & Controls & \multicolumn{2}{c}{$\begin{array}{c}\text { One phase of head and neck } \\
\text { irradiation }\end{array}$} \\
\cline { 2 - 4 } & $\mathbf{0 ~ G y}$ & $\mathbf{0 . 5}$ Gy & 2 Gy \\
\hline AUC $(\mathrm{min} \mu \mathrm{g} / \mathrm{mL})$ & $4748 \pm 360$ & $4017 \pm 358^{*}$ & $3993 \pm 191^{*}$ \\
$\mathrm{t}_{1 / 2}(\mathrm{~min})$ & $33.1 \pm 11.5$ & $35.5 \pm 9.7$ & $39.0 \pm 5.6$ \\
$\mathrm{Cmax}(\mu \mathrm{g} / \mathrm{mL})$ & $165 \pm 35$ & $165 \pm 17$ & $167 \pm 39$ \\
$\mathrm{MRT}(\mathrm{min})$ & $37.0 \pm 2.8$ & $30 \pm 4.5^{*}$ & $29 \pm 2.9^{*}$ \\
$\mathrm{CL}(\mathrm{mL} / \mathrm{kg} / \mathrm{min})$ & $21.2 \pm 1.7$ & $25 \pm 4.8$ & $27 \pm 5.7^{*}$ \\
Vss $(\mathrm{mL} / \mathrm{kg})$ & $785 \pm 96$ & $784 \pm 88$ & $815 \pm 130$ \\
\hline
\end{tabular}

$A \cup C$ area under the plasma concentration, vs. time curve, $t_{1 / 2}$ terminal elimination phase half-life, Cmax maximum observed plasma concentration, MRT mean residence time, $C L$ total plasma clearance, $V s s$ volume of distribution at steady state. *The mean difference is significant at the 0.05 level in comparison to the control group.

contrast, increased the CL of CDDP at $0.5 \mathrm{~Gy}(p=0.02)$ and 2 Gy $(p=0.019)$ when compared to non-irradiated controls (Table 3). There was no significant difference in the values of MRT, Vss and $t_{1 / 2}$ within any group.

Head and neck irradiation markedly increased the AUC of CDDP in bile of rats by $0.5 \mathrm{~Gy}(p=0.015)$ and at 2 Gy $(p=0.003)$, respectively (Figure 4B). When compared to non-irradiated controls, head and neck irradiation significantly increased CL of CDDP at 0.5 Gy $(p=0.001)$ and 2 Gy $(p=<0.001)$, respectively. There was no statistically significant difference for $\mathrm{Cmax}_{1 / 2}, \mathrm{~T}_{1 / 2} \mathrm{MRT}$ and Vss. (Table 4).

\section{Discussion}

From 2DRT to arc therapy techniques, these therapies are supposed to produce greater target dose conformity and better critical organ sparing effects, allowing target dose escalation, with lower toxicity to normal tissues [10,31-33]. However, the more beam arranged the more accompanied low-dose distribution to the torso are noted. Figures 1 and 2 illustrated the example of isodose distribution with 2 Gy to the targets in head and neck patient using the different techniques. We noted that more than $50 \%$ of the normal organ was exposed to 0.5 Gy during daily 2-Gy radiation treatments, except when using 2DRT to treat patients. These dose-painting characteristics of modern radiation technique are also noted in other part of body's treatment [17]. It suggests that the low-dose radiation area generously deposits around the target volume, especially when advanced, conformal radiation techniques are used.

In the previous studies, we confirm that abdominal or pelvic irradiation modulates the systemic PK of 5-FU at $0.5 \mathrm{~Gy}$, off-target area in clinical practice, and at $2 \mathrm{~Gy}$, the daily treatment dose for target treatment in an experimental rat model $[17,18]$. Additionally, the RT-PK phenomena are related to the releasing of MMP-8 [18]. The liver and kidneys are excluded in the previous study to rule out the influences caused by irradiated these parts because of $80 \%$ of 5 -FU is catabolized by the liver $[34,35]$ and $10 \%$ to $20 \%$ of 5 -FU is excreted by the kidneys [36]. Furthermore, polymorphonuclear neutrophils (PMNs) are the main source of MMP-8 in humans and mice $[37,38]$ and 5-FU often induces leukocyte infiltration of rat small intestine by the gastrointestinal toxicity [19]. Additionally, 5-FU is highly absorbable in a gastric emptying-limited manner with first-pass metabolism concerning [39] and the uptake of 5-FU in intestinal also influences by passive transport and carrier-mediated transport [20]. Therefore, it is difficult to specify the PK of 5-FU modulated by RT is a general phenomena especially when RT field still cover partial intestines.

In the current study, only $\mathrm{HN}$ was irradiated for PK analysis. (Figure 1) the AUC of 5-FU in rats was reduced not only at 0.5 Gy but also at 2 Gy. (Figure 3A) Additionally, the AUC of 5-FU in bile of rats after $\mathrm{HN}$ irradiation increased for both irradiation groups. (Figure 4A) Furthermore, the CL rate in irradiation groups were increased in plasma and decreased in bile study. (Tables 1 and 2) It suggests that local irradiation may modulate the systemic PK of 5-FU and facilitate the excretion of 5-FU discernible to the area irradiated.

CDDP and 5-FU combination treatments are reported to be one of the most active chemotherapeutic regimens for the patients with head and neck squamous cell carcinoma [4-6]. Although both CDDP and 5-FU induce apoptosis through caspase activation, the apoptosis induced by CDDP was reported to be involved in caspase-9 [40], in contrast to the involvement of caspase- $1,-3$ and -8 in 5-FU-induced apoptosis [41]. Additionally, CDDP is known to intercalate into DNA at any phase of the cell cycle $[42,43]$, causing the cytotoxic effect and reducing the cellular viability [44]. 5-FU inhibits the function of RNA or DNA synthesis $[45,46]$ and causes the cytostatic effect accompanied by the growth arrest at the G1/S boundary of the cell cycle [47]. In this study, the AUC of CDDP in plasma was decreased no matter at 0.5 Gy or 2 Gy (Figure $3 \mathrm{~B}$ ) and increased the CL of CDDP when compared to non-irradiated controls (Table 3). Additionally, the AUC of CDDP in bile of rats was increased by $0.5 \mathrm{~Gy}$ and 2 Gy. (Figure 4B) (Table 4). It suggests that similar modulation also between head and neck irradiation and the systemic PK of CDDP with facilitating the excretion of CDDP. Irradiation is not only modulating PK of 5-FU but also modulating PK of CDDP. Because this RT-PK phenomenon exists in drugs with different mechanisms of action, it implicates that RT may modulate PK in a way independent to downstream drug targets. 

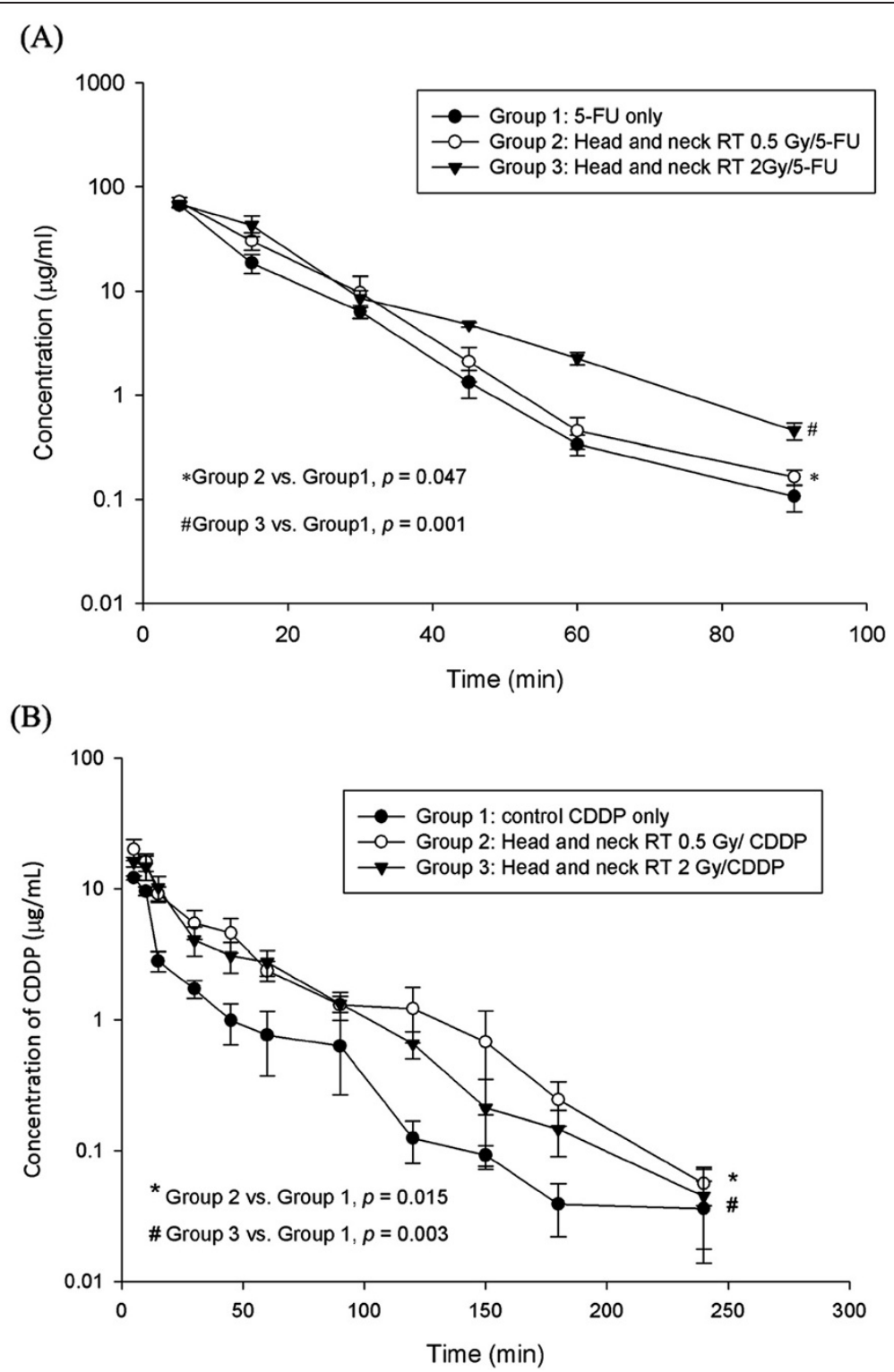

Figure 4 The area under the bile concentration vs. time curve (AUC) of (A) 5 -FU $100 \mathrm{mg} / \mathrm{kg}$ (B) Cisplatin $5 \mathrm{mg} / \mathrm{kg}$ to rats in the control, 0.5 and 2 Gy groups with head and neck irradiation.

There are some limitations in the current study. First, the role of MMP- 8 as observed in abdominal and pelvic $\mathrm{RT}$ is not proved in the current study. The role of abdominal and pelvic RT-induced MMP-8 in modulating 5-FU pharmacokinetics has been demonstrated. Whether this soluble factor has an impact on head and neck RTmodulated pharmacokinetics of 5-FU and CDDP remains to be determined. Second, this study is the effects of irradiation followed by chemotherapy with one-shot design rather than fractionation RT as daily practice. For proof of concept, we designed the use of one shot irradiation followed by chemotherapy. In clinical use of fractionated
RT and periodically concurrent chemotherapy, the previous daily fraction of RT may modulate the PK of chemotherapeutics administered in the consecutive day. In the conducting clinical trial, we planned to validate this RTmodulated PK phenomenon in patients receiving CCRT with fractionated RT. Third, this study is the effects of irradiation followed by chemotherapy but concurrent chemotherapy with radiotherapy is the usual way that applied in the clinical practice. However, patients with rectal cancer who receive preoperative radiotherapy, add ing fluorouracil-based chemotherapy preoperatively or postoperatively has no significant effect on survival. 
Table 2 Pharmacokinetic parameters of 5-Fluorouracil (100 $\mathrm{mg} / \mathrm{kg}$, i.v.) in rats bile after head and neck irradiation with and without 0.5 and $2 \mathrm{~Gy}$

\begin{tabular}{lccc}
\hline Parameters & Controls & \multicolumn{2}{c}{$\begin{array}{c}\text { One phase of head and neck } \\
\text { irradiation }\end{array}$} \\
\cline { 2 - 4 } & $\mathbf{0 ~ G y}$ & $\mathbf{0 . 5}$ Gy & 2 Gy \\
\hline AUC (min $\mu \mathrm{g} / \mathrm{mL})$ & $1218 \pm 22$ & $1366 \pm 86^{*}$ & $1522 \pm 111^{*}$ \\
$\mathrm{t}_{1 / 2}(\mathrm{~min})$ & $9.4 \pm 0.5$ & $9.2 \pm 0.2$ & $13.3 \pm 1.1^{*}$ \\
$\mathrm{Cmax}(\mu \mathrm{g} / \mathrm{mL})$ & $129 \pm 22$ & $104 \pm 14^{*}$ & $88 \pm 17^{*}$ \\
$\mathrm{MRT}(\mathrm{min})$ & $10.0 \pm 1.0$ & $10.7 \pm 0.5$ & $14.5 \pm 0.6^{*}$ \\
$\mathrm{CL}(\mathrm{mL} / \mathrm{kg} / \mathrm{min})$ & $80.3 \pm 2.3$ & $76.3 \pm 5.4$ & $65.6 \pm 4.5^{*}$ \\
Vss $(\mathrm{mL} / \mathrm{kg})$ & $812 \pm 96$ & $820 \pm 66$ & $952 \pm 69$ \\
\hline AUC
\end{tabular}

AUC area under the plasma concentration, vs. time curve, $t_{1 / 2}$ terminal elimination phase half-life, Cmax maximum observed plasma concentration, MRT mean residence time, $C L$ total plasma clearance, Vss volume of distribution at steady state.

*The mean difference is significant at the 0.05 level in comparison to the control group.

Chemotherapy, regardless of time sequence, confers a significant benefit with respect to local control [48]. Additionally, fluorouracil and cisplatin to radiotherapy within 16 hours after the first radiation fraction was administered that significantly improved the survival rate of women with locally advanced cervical cancer [49]. These data explain the importance of adding chemotherapy to RT but rather than time sequence of drug delivering. The findings for modulation of drug PK by local RT, as demonstrated in previous and this study, may provide a clue and a research platform to clarify this controversy. Finally, the data of pharmacokinetics for head and neck cancer patients during CCRT is not collected in the current study. Thus, the further study

Table 3 Pharmacokinetic parameters of CDDP $(5 \mathrm{mg} / \mathrm{kg}$, i.v.) in rats plasma after with or without head \& neck irradiation at control, 0.5 and $2 \mathrm{~Gy}$

\begin{tabular}{lccc}
\hline Parameters & Controls & \multicolumn{2}{c}{$\begin{array}{c}\text { One phase of head and neck } \\
\text { irradiation }\end{array}$} \\
\cline { 2 - 4 } & $\mathbf{0 ~ G y}$ & $\mathbf{0 . 5}$ Gy & 2 Gy \\
\hline AUC $(\mathrm{min} \mu \mathrm{g} / \mathrm{mL})$ & $722 \pm 164$ & $484 \pm 52^{*}$ & $511 \pm 138^{*}$ \\
$\mathrm{t}_{1 / 2}(\mathrm{~min})$ & $269 \pm 108$ & $215 \pm 88.5$ & $172 \pm 44.6$ \\
$\mathrm{Cmax}(\mu \mathrm{g} / \mathrm{mL})$ & $15.0 \pm 2.2$ & $9.6 \pm 0.7^{*}$ & $10.1 \pm 1.3^{*}$ \\
$\mathrm{MRT}(\mathrm{min})$ & $291 \pm 131$ & $248 \pm 97.5$ & $249 \pm 116$ \\
$\mathrm{CL}(\mathrm{mL} / \mathrm{kg} / \mathrm{min})$ & $4 \pm 1.2$ & $6.8 \pm 1.1^{*}$ & $6 \pm 0.9^{*}$ \\
VsS $(\mathrm{mL} / \mathrm{kg})$ & $1233 \pm 470$ & $1621 \pm 520$ & $1626 \pm 683$
\end{tabular}

$A \cup C$ area under the plasma concentration, vs. time curve, $t_{1 / 2}$ terminal elimination phase half-life, Cmax maximum observed plasma concentration, MRT mean residence time, $C L$ total plasma clearance, $V s s$ volume of distribution at steady state.

*The mean difference is significant at the 0.05 level in comparison to the control group.
Table 4 Pharmacokinetic parameters of CDDP $(5 \mathrm{mg} / \mathrm{kg}$, i.v.) in rats bile after head and neck irradiation with and without 0.5 and $2 \mathrm{~Gy}$

\begin{tabular}{lccc}
\hline Parameters & Controls & \multicolumn{2}{c}{$\begin{array}{c}\text { One phase of head and neck } \\
\text { irradiation }\end{array}$} \\
\cline { 2 - 4 } & $\mathbf{0 ~ G y}$ & $\mathbf{0 . 5} \mathbf{~ G y}$ & $\mathbf{2 ~ G y}$ \\
\hline AUC $(\mathrm{min} \mu \mathrm{g} / \mathrm{mL})$ & $262 \pm 52$ & $542 \pm 192^{*}$ & $611 \pm 66^{*}$ \\
$\mathrm{t}_{1 / 2}(\mathrm{~min})$ & $32 \pm 15$ & $27 \pm 5.1$ & $28 \pm 7.8$ \\
$\mathrm{Cmax}(\mu \mathrm{g} / \mathrm{mL})$ & $12 \pm 1.0$ & $19 \pm 10$ & $18 \pm 2.8$ \\
$\mathrm{MRT}(\mathrm{min})$ & $28 \pm 9.4$ & $33 \pm 8.3$ & $32 \pm 11.6$ \\
$\mathrm{CL}(\mathrm{mL} / \mathrm{kg} / \mathrm{min})$ & $19 \pm 3.4$ & $10 \pm 2.9^{*}$ & $8.2 \pm 0.9^{*}$ \\
Vss $(\mathrm{mL} / \mathrm{kg})$ & $544 \pm 202$ & $337 \pm 150$ & $257 \pm 94$ \\
\hline
\end{tabular}

AUC area under the plasma concentration, vs. time curve, $t_{1 / 2}$ terminal elimination phase half-life, Cmax maximum observed plasma concentration $M R T$ mean residence time, $C L$ total plasma clearance, Vss volume of distribution at steady state.

*The mean difference is significant at the 0.05 level in comparison to the control group.

for RT-PK phenomena of 5-FU and CDDP in head and neck cancer patients is warranted in the future.

\section{Conclusions}

To our best knowledge, this is the first study to prove that head and neck irradiation without liver, kidneys and intestines irradiation that can significantly modulate the systemic pharmacokinetics of 5-FU and CDDP at dosage levels for both the target (2 Gy) and off-target areas (0.5 Gy). This study may provide an experimental clue to understand the unclear biological effects of generous, low-dose RT in the era of highly conformal RT in head and neck treatment. For head and neck irradiation with concurrent 5-FU and CDDP, this unexpected RT-PK phenomena may provide a reference for adjustment of drug administration during CCRT and is worthy of further investigation in clinical practice.

\section{Competing interest}

The authors declare that they have no competing interests.

\section{Authors' contributions}

$\mathrm{CH}$ Hsieh participated in the design of the study, performed the radiation and pharmacokinetic experiments, and wrote the manuscript. ML Hou and $\mathrm{MH}$ Chiang helped $\mathrm{CH}$ Hsieh to do some experiments. HC Tai and HJ Tien was responsible for the radiation planning. LY Wang helped to design the experiments. TH Tsai and YJ Chen initiated, organized and supervised all the work, including the manuscript. All authors read and approved the final version of this manuscript.

\section{Acknowledgement}

This work was supported by the Far Eastern Memorial Hospital grants (FEMH-2012-C-055; FEMH 101-2314-B-418 -010 -MY3), the National Science Council (NSC 101-2314-B-418 -010 -MY3) and MMH-100-01, MMH-101-01, and MMH-E-102-13.

\section{Author details}

${ }^{1}$ Division of Radiation Oncology, Department of Radiology, Far Eastern Memorial Hospital, Taipei, Taiwan. ${ }^{2}$ Institute of Traditional Medicine, School 
of Medicine, National Yang-Ming University, 155, Li-Nong Street Section 2, Taipei 112, Taiwan. ${ }^{3}$ Department of Medicine, School of Medicine, National Yang-Ming University, Taipei, Taiwan. ${ }^{4}$ Department of Radiation Oncology, Mackay Memorial Hospital, 92, Chung-Shan North Road, Taipei, Taiwan.

${ }^{5}$ Department of Medical Research, Mackay Memorial Hospital, Taipei, Taiwan. ${ }^{6}$ Department of Education and Research, Taipei City Hospital, Taipei, Taiwan. ${ }^{7}$ School and Graduate Institute of Physical Therapy, College of Medicine, National Taiwan University, Taipei, Taiwan.

Received: 2 May 2013 Accepted: 10 September 2013

Published: 26 September 2013

\section{References}

1. Adelstein DJ, Lavertu P, Saxton JP, Secic M, Wood BG, Wanamaker JR, Eliachar I, Strome M, Larto MA: Mature results of a phase III randomized trial comparing concurrent chemoradiotherapy with radiation therapy alone in patients with stage III and IV squamous cell carcinoma of the head and neck. Cancer 2000, 88:876-883.

2. Bernier J, Domenge C, Ozsahin M, Matuszewska K, Lefebvre JL, Greiner RH, Giralt J, Maingon P, Rolland F, Bolla M, et al: Postoperative irradiation with or without concomitant chemotherapy for locally advanced head and neck cancer. N Engl J Med 2004, 350:1945-1952.

3. Cooper JS, Pajak TF, Forastiere AA, Jacobs J, Campbell BH, Saxman SB, Kish JA, Kim HE, Cmelak AJ, Rotman M, et al: Postoperative concurrent radiotherapy and chemotherapy for high-risk squamous-cell carcinoma of the head and neck. N Engl J Med 2004, 350:1937-1944.

4. Andreadis C, Vahtsevanos K, Sidiras T, Thomaidis I, Antoniadis K, Mouratidou D: 5-Fluorouracil and cisplatin in the treatment of advanced oral cancer. Oral Oncol 2003, 39:380-385.

5. Amrein PC, Weitzman SA: Treatment of squamous-cell carcinoma of the head and neck with cisplatin and 5-fluorouracil. J Clin Oncol 1985, 3:1632-1639.

6. Kish JA, Ensley JF, Jacobs J, Weaver A, Cummings G, Al-Sarraf M: A randomized trial of cisplatin (CACP) + 5-fluorouracil (5-FU) infusion and $\mathrm{CACP}+5$-FU bolus for recurrent and advanced squamous cell carcinoma of the head and neck. Cancer 1985, 56:2740-2744.

7. Verhey LJ: Comparison of three-dimensional conformal radiation therapy and intensity-modulated radiation therapy systems. Semin Radiat Oncol 1999, 9:78-98.

8. Shueng PW, Lin SC, Chong NS, Lee HY, Tien HJ, Wu LJ, Chen CA, Lee JJ, Hsieh $\mathrm{CH}$ : Total marrow irradiation with helical tomotherapy for bone marrow transplantation of multiple myeloma: first experience in Asia. Technol Cancer Res Treat 2009, 8:29-38.

9. Chao KS, Low DA, Perez CA, Purdy JA: Intensity-modulated radiation therapy in head and neck cancers: The Mallinckrodt experience. Int J Cancer 2000, 90:92-103.

10. Tai HC, Hsieh CH, Chao KS, Liu SH, Leu YS, Chang YF, Hsiao HT, Chang YC, Huang DY, Chen YJ: Comparison of radiotherapy strategies for locally advanced hypopharyngeal cancer after resection and ileocolic flap reconstruction. Acta Otolaryngol 2009, 129:311-317.

11. Shueng PW, Shen BJ, Wu LJ, Liao LJ, Hsiao CH, Lin YC, Cheng PW, Lo WC, Jen YM, Hsieh CH: Concurrent image-guided intensity modulated radiotherapy and chemotherapy following neoadjuvant chemotherapy for locally advanced nasopharyngeal carcinoma. Radiat Oncol 2011, 6:95

12. Shueng PW, Lin SC, Chang HT, Chong NS, Chen YJ, Wang LY, Hsieh YP, Hsieh $\mathrm{CH}$ : Toxicity risk of non-target organs at risk receiving low-dose radiation: case report. Radiat Oncol 2009, 4:71

13. Hsieh CH, Chang HT, Lin SC, Chen YJ, Wang LY, Hsieh YP, Chen CA, Chong NS, $\mathrm{Lin} S \mathrm{~L}$, Chen CY, et al: Toxic risk of stereotactic body radiotherapy and concurrent helical tomotherapy followed by erlotinib for non-small-cell lung cancer treatment-case report. BMC Cancer 2010, 10:696.

14. Morgan WF: Non-targeted and delayed effects of exposure to ionizing radiation: I. Radiation-induced genomic instability and bystander effects in vitro. Radiat Res 2003, 159:567-580.

15. Mothersill C, Seymour CB: Radiation-induced bystander effects-implications for cancer. Nat Rev Cancer 2004, 4:158-164.

16. Kaminski JM, Shinohara E, Summers JB, Niermann KJ, Morimoto A, Brousal J: The controversial abscopal effect. Cancer Treat Rev 2005, 31:159-172.

17. Hsieh CH, Hsieh YJ, Liu CY, Tai HC, Huang YC, Shueng PW, Wu L, Wang LY, Tsai TH, Chen YJ: Abdominal irradiation modulates 5-Fluorouracil pharmacokinetics. J Trans/ Med 2010, 8:29.
18. Hsieh CH, Liu CY, Hsieh YJ, Tai HC, Wang LY, Tsai TH, Chen YJ: Matrix metalloproteinase- 8 mediates the unfavorable systemic impact of local irradiation on pharmacokinetics of anti-cancer drug 5-Fluorouracil. PLOS ONE 2011, 6:e21000.

19. Hirata K, Horie T: A prostaglandin E1 analog, OP-1206, alleviates 5 -fluorouracil-induced injury of rat small intestine. Res Commun Mol Pathol Pharmacol 1999, 104:243-251.

20. Yuasa $H$, Matsuhisa E, Watanabe J: Intestinal brush border transport mechanism of 5-fluorouracil in rats. Biol Pharm Bull 1996, 19:94-99.

21. Marcu L, van Doorn T, Olver I: Cisplatin and radiotherapy in the treatment of locally advanced head and neck cancer-a review of their cooperation. Acta Oncol 2003, 42:315-325.

22. Dewit L: Combined treatment of radiation and cisdiamminedichloroplatinum (II): a review of experimental and clinical data. Int J Radiat Oncol Biol Phys 1987, 13:403-426.

23. Coughlin CT, Richmond RC: Biologic and clinical developments of cisplatin combined with radiation: concepts, utility, projections for new trials, and the emergence of carboplatin. Semin Oncol 1989, 16:31-43.

24. Sorenson CM, Barry MA, Eastman A: Analysis of events associated with cell cycle arrest at G2 phase and cell death induced by cisplatin. $J$ Natl Cancer Inst 1990, 82:749-755.

25. Sorenson CM, Eastman A: Mechanism of cis-diamminedichloroplatinum (II)-induced cytotoxicity: role of G2 arrest and DNA double-strand breaks. Cancer Res 1988, 48:4484-4488.

26. Sorenson CM, Eastman A: Influence of cis-diamminedichloroplatinum(II) on DNA synthesis and cell cycle progression in excision repair proficient and deficient Chinese hamster ovary cells. Cancer Res 1988, 48:6703-6707.

27. Pawlik TM, Keyomarsi K: Role of cell cycle in mediating sensitivity to radiotherapy. Int J Radiat Oncol Biol Phys 2004, 59:928-942.

28. Yoshikawa A, Saura R, Matsubara T, Mizuno K: A mechanism of cisplatin action: antineoplastic effect through inhibition of neovascularization. Kobe J Med Sci 1997, 43:109-120.

29. Jarugula VR, Lam SS, Boudinot FD: Nonlinear pharmacokinetics of 5-fluorouracil in rats. J Pharm Sci 1997, 86:756-758.

30. Prajda N, Kralovanszky J, Gal F, Kiss F, Kerpel-Fronius S: Evaluation of side effects of platinum complexes (CDDP, CBDCA, CHIP) on rat bone marrow. In Vivo 1989, 3:267-270.

31. Hsieh CH, Kuo YS, Liao LJ, Hu KY, Lin SC, Wu LJ, Lin YC, Chen YJ, Wang LY, Hsieh YP, et al: Image-guided intensity modulated radiotherapy with helical tomotherapy for postoperative treatment of high-risk oral cavity cancer. BMC Cancer 2011, 11:37.

32. Hsieh CH, Wei MC, Lee HY, Hsiao SM, Chen CA, Wang LY, Hsieh YP, Tsai TH, Chen YJ, Shueng PW: Whole pelvic helical tomotherapy for locally advanced cervical cancer: technical implementation of IMRT with helical tomothearapy. Radiat Oncol 2009, 4:62.

33. Shueng PW, Wu LJ, Chen SY, Hsiao CH, Tien HJ, Cheng PW, Kuo YS, Chen YJ, Chen CA, Hsieh PY, et al: Concurrent chemoradiotherapy with helical tomotherapy for oropharyngeal cancer: a preliminary result. Int J Radiat Oncol Biol Phys 2010, 77:715-721.

34. Bocci G, Danesi R, Di Paolo AD, Innocenti F, Allegrini G, Falcone A, Melosi A, Battistoni M, Barsanti G, Conte PF, et al: Comparative pharmacokinetic analysis of 5-fluorouracil and its major metabolite 5-fluoro-5,6-dihydrouracil after conventional and reduced test dose in cancer patients. Clin Cancer Res 2000, 6:3032-3037.

35. Casale F, Canaparo R, Serpe L, Muntoni E, Pepa CD, Costa M, Mairone L, Zara GP, Fornari G, Eandi M: Plasma concentrations of 5-fluorouracil and its metabolites in colon cancer patients. Pharmacol Res 2004, 50:173-179.

36. Peters GJ: Antimetabolites. In Oxford textbook of oncology. Edited by Peckam M, Pinedo HM, Veronesi U. London: Oxford University Press; 1995:524-552.

37. Owen CA, Hu Z, Lopez-Otin C, Shapiro SD: Membrane-bound matrix metalloproteinase-8 on activated polymorphonuclear cells is a potent, tissue inhibitor of metalloproteinase-resistant collagenase and serpinase. J Immunol 2004, 172:7791-7803.

38. Balbin M, Fueyo A, Knauper V, Pendas AM, Lopez JM, Jimenez MG, Murphy G, Lopez-Otin C: Collagenase 2 (MMP-8) expression in murine tissue-remodeling processes. Analysis of its potential role in postpartum involution of the uterus. J Biol Chem 1998, 273:23959-23968.

39. Yuasa H, Matsuda K, Gu J, Suzuki E, Yokouchi I, Watanabe J: Dose-dependent gastrointestinal absorption of 5-fluorouracil in rats in vivo. Biol Pharm Bull 1996, 19:1494-1498. 
40. Kuwahara D, Tsutsumi K, Kobayashi T, Hasunuma T, Nishioka K: Caspase-9 regulates cisplatin-induced apoptosis in human head and neck squamous cell carcinoma cells. Cancer Lett 2000, 148:65-71.

41. Ohtani T, Hatori M, Ito H, Takizawa K, Kamijo R, Nagumo M: Involvement of caspases in 5-FU induced apoptosis in an oral cancer cell line. Anticancer Res 2000, 20:3117-3121.

42. Drewinko B, Brown BW, Gottlieb JA: The effect of cis-diamminedichloroplatinum (II) on cultured human lymphoma cells and its therapeutic implications. Cancer Res 1973, 33:3091-3095.

43. Zwelling LA, Kohn KW: Mechanism of action of cis-dichlorodiammineplatinum (II). Cancer Treat Rep 1979, 63:1439-1444.

44. Okamura M, Kobayashi M, Suzuki F, Shimada J, Sakagami H: Induction of cell death by combination treatment with cisplatin and 5 -fluorouracil in a human oral squamous cell carcinoma cell line. Anticancer Res 2007, 27:3331-3337.

45. Spiegelman S, Sawyer R, Nayak R, Ritzi E, Stolfi R, Martin D: Improving the anti-tumor activity of 5-fluorouracil by increasing its incorporation into RNA via metabolic modulation. Proc Natl Acad Sci USA 1980, 77:4966-4970.

46. Parker WB, Cheng YC: Metabolism and mechanism of action of 5-fluorouracil. Pharmacol Ther 1990, 48:381-395.

47. Li MH, Ito D, Sanada M, Odani T, Hatori M, Iwase M, Nagumo M: Effect of 5-fluorouracil on G1 phase cell cycle regulation in oral cancer cell lines. Oral Oncol 2004, 40:63-70.

48. Bosset JF, Collette L, Calais G, Mineur L, Maingon P, Radosevic-Jelic L, Daban A, Bardet $E$, Beny A, Ollier JC: Chemotherapy with preoperative radiotherapy in rectal cancer. N Engl J Med 2006, 355:1114-1123.

49. Eifel PJ, Winter K, Morris M, Levenback C, Grigsby PW, Cooper J, Rotman M, Gershenson D, Mutch DG: Pelvic irradiation with concurrent chemotherapy versus pelvic and para-aortic irradiation for high-risk cervical cancer: an update of radiation therapy oncology group trial (RTOG) 90-01. J Clin Oncol 2004, 22:872-880.

doi:10.1186/1479-5876-11-231

Cite this article as: Hsieh et al.: Head and neck irradiation modulates pharmacokinetics of 5-fluorouracil and cisplatin. Journal of Translational Medicine 2013 11:231.

\section{Submit your next manuscript to BioMed Central and take full advantage of:}

- Convenient online submission

- Thorough peer review

- No space constraints or color figure charges

- Immediate publication on acceptance

- Inclusion in PubMed, CAS, Scopus and Google Scholar

- Research which is freely available for redistribution 